\title{
Paul CHOPELIN, Ville patriote, ville martyre
}

Lyon, l'Église et la Révolution, 1788-1805, Paris, Letouzey et Ané, 2010, $463 \mathrm{p}$.

\section{Marie Deman}

\section{OpenEdition}

\section{Journals}

\section{Édition électronique}

URL : https://journals.openedition.org/ahrf/12634

DOI : $10.4000 /$ ahrf.12634

ISSN : 1952-403X

Éditeur :

Armand Colin, Société des études robespierristes

\section{Édition imprimée}

Date de publication : 1 septembre 2012

Pagination : 159-160

ISBN : 978-2-200-92761-5

ISSN : 0003-4436

\section{Référence électronique}

Marie Deman, "Paul CHopelin, Ville patriote, ville martyre », Annales historiques de la Révolution française [En ligne], 369 | juillet-septembre 2012, mis en ligne le 28 février 2013, consulté le 23 avril 2022. URL http://journals.openedition.org/ahrf/12634 ; DOl : https://doi.org/10.4000/ahrf.12634

Ce document a été généré automatiquement le 23 avril 2022

Tous droits réservés 


\section{Paul CHOPELIN, Ville patriote, ville}

\section{martyre}

Lyon, l’Église et la Révolution, 1788-1805, Paris, Letouzey et Ané, 2010, $463 \mathrm{p}$.

\section{Marie Deman}

\section{RÉFÉRENCE}

Paul CHOPELIN, Ville patriote, ville martyre. Lyon, l'Église et la Révolution, 1788-1805, Paris, Letouzey et Ané, 2010, 463 p., ISBN 978 2-7063-0270-1, 38,50€.

1 Dans cet ouvrage issu de sa thèse, Paul Chopelin propose une approche nouvelle de l'histoire religieuse de Lyon en Révolution, en introduisant un paramètre supplémentaire dans son analyse : le rôle des fidèles.

2 L'auteur se penche d'abord sur la pré-révolution et dresse un tableau d'une ville encore marquée par l'héritage tridentin, sous la férule des chanoines-comtes de Lyon; à la fin de l'Ancien Régime, cependant, elle se sécularise lentement, révélant un clivage et une inadaptation d'une partie de l'Église, notamment régulière, aux changements du temps. La présence de nombreuses confréries, dévotions et d'associations laïques plus ou moins secrètes atteste de la vitalité religieuse de Lyon et de la participation active des habitants à la vie spirituelle, préfigurant ainsi une implication dans les affaires confessionnelles durant la décennie révolutionnaire.

3 Avec les prémices de la Révolution, les relations au sein de l'Église lyonnaise se radicalisent. L'action du nouvel archevêque de Lyon, Marbeuf, à compter de 1788, confirme d'abord le choix d'épurer le clergé de la ville de ses convulsionnaires. Cette césure se confirme lors des réunions d'élection des États généraux et de rédaction des cahiers de doléances au cours desquelles les curés imposent leurs vues dans les cahiers, malgré une opposition farouche des prélats. Les autres cahiers abordent peu la question religieuse, se bornant, comme dans le reste du royaume, à réclamer une meilleure utilisation des biens ecclésiastiques par exemple. Le bref sentiment d'unité 
suscité au sein de la ville (à l'exception de l'archevêque) par la réunion des trois ordres en Assemblée constituante est l'occasion pour les populations de s'impliquer pour la première fois de la Révolution dans les affaires religieuses, notamment par le biais de prospectus de la Société philanthropique de Lyon. Mais le clergé séculier s'investit aussi dans la vie politique locale au moment des premières élections municipales. Pourtant, des incidents se multiplient rapidement entre révolutionnaires et clergé, signes d'une tension grandissante, malgré l'apparente concorde lyonnaise.

C'est l'application des différentes lois relatives à la Constitution civile du clergé qui précipite la scission entre les partisans et les opposants à la politique religieuse de la Révolution française. Les curés sont rapidement confrontés à la question du serment constitutionnel tout comme leurs fidèles impliqués parfois dans le choix de leur pasteur. Bien que ce ne soit pas le premier serment qu'ils aient eu à prêter, les curés se distinguent par leur prise de position rapide (tous prêtent serment et la moitié d'entre eux se rétracte dans la foulée). Très rapidement, la question du statut des réfractaires « sans paroisses » interdits d'officier et des « rétractés », soutenus pour partie par leurs ouailles, se pose, même si une partie d'entre eux sont maintenus en poste le temps de leur trouver un remplaçant. Les constitutionnels, guidés par leur nouvel évêque Lamourette posent les bases d'un culte nouveau, plus simple dans sa forme et teinté de références patriotiques, afin de se rapprocher de leurs ouailles. Les fidèles deviennent ainsi, pour l'auteur, les principaux enjeux et des acteurs de premier ordre de la politique religieuse: séduits, craints, engagés aux côtés du réfractaire ou du constitutionnel dans le fonctionnement de l'Eglise, ils multiplient les actions dans la sphère publique, parfois violemment.

5 Après les massacres du 9 septembre 1792, un temps nouveau pour l'Église de Lyon commence : défini par l'auteur comme "temps des martyrs", il se caractérise par un durcissement des lois et des conditions de vie des ecclésiastiques, qu'ils soient réfractaires (unanimes par leur refus du serment de liberté-égalité, poussés dans la clandestinité en ville ou à l'étranger, avant de revenir discrètement en ville), mais aussi constitutionnels aux prises avec une municipalité plus «jacobine ». La parenthèse de l'insurrection lyonnaise est cependant l'occasion pour eux, mais aussi pour les fidèles, de s'engager comme citoyens aux côtés des nouvelles autorités et durant le siège de la ville. Une fois l'ordre rétabli, des cultes aux formes multiples sont mis en place: cérémonies expiatoires à la mémoire du martyre de Chalier, célébrations de la Raison plus ou moins organisées, culte de l'Être Suprême, fête de l'âne destinée à laïciser l'espace public, maintien des cultes constitutionnel, réfractaire et minoritaire, malgré les procès nombreux qui aboutissent à la condamnation de non assermentés. Paul Chopelin souligne à nouveau le rôle joué par les laïcs dans l'organisation des cultes ou la protection des réfractaires.

6 Pourtant, la sortie de la Terreur, loin d'apaiser les tensions religieuses, ravive l'opposition entre réfractaires et constitutionnels, désormais concurrents dans une même paroisse et un même culte. L'application du décret du 11 prairial an III s'avère délicate. Par ailleurs, les fidèles confirment leur rôle moteur dans l'organisation du culte. Exerçant une forme de citoyenneté religieuse, ils se battent pour la réouverture des lieux de culte, soutiennent les constitutionnels, les réfractaires, constituant un maillage relationnel et logistique autour d'eux et à nouveau, les femmes occupent une place de premier plan. Mais cette période de relative tolérance prend fin avec le décret du 19 fructidor an $\mathrm{V}$, ce qui a comme conséquence immédiate de relancer le culte 
clandestin, dans lequel les fidèles, notamment les jeunes, renforcent leur rôle logistique, particulièrement dans l'hébergement des prêtres. La mort de Mgr de Marbeuf plonge pourtant le clergé insermenté dans une crise engendrée par la vacance $\mathrm{du}$ siège, ce qui provoque une désorganisation du culte réfractaire sans que l'auteur ait pu déterminer une éventuelle implication des fidèles. Le clergé constitutionnel achève, lui, son organisation, toujours avec le soutien logistique et financier de ses fidèles. La signature du Concordat (15 juillet 1801) ne sonne pas le début de la réconciliation entre les deux clergés ; pour que celle-ci s'esquisse, il faut attendre l'action du nouvel évêque Joseph Fesch, qui s'emploie à réunifier le clergé de Lyon, non sans mal, à éteindre les derniers feux d'une religion civique et à appliquer les articles du Concordat. Là encore, Paul Chopelin souligne le rôle des fidèles dans la nouvelle Église lyonnaise. Mgr Fesch, sans doute conscient de l'importance jouée par ces croyants dans la vie religieuse de la ville pendant la Révolution, choisit de les replacer sous le contrôle du clergé et de les écarter des affaires ecclésiastiques en contrôlant notamment les fabriques.

Déchirée, l'Église de Lyon l'a été dès les premiers soubresauts de la Révolution française. Foyer à la fois d'un intense mouvement de réfractaires, d'un réseau organisé de prêtres constitutionnels et d'un bastion de prêtres émigrés, la ville a aussi connu une sécularisation et une baisse de la pratique religieuse, favorisées par l'anticléricalisme et les politiques religieuses. Mais ce qui ressort du riche et original ouvrage de Paul Chopelin est certainement son analyse de l'histoire religieuse de la ville portée sur et par les fidèles, qui amène à repenser le rôle de ces populations, tant attachées à leur culte, dans la régénération de l'Église de France. 